\title{
Like Community, Like Language: Seventy-Five Years of Sindhi in Post-Partition India
}

\author{
Arvind Iyengar | ORCID: 0000-0002-7303-1524 \\ University of New England, Armidale, New South Wales, Australia \\ arvind.iyengar@une.edu.au \\ Sundri Parchani \\ Independent Researcher, Pune, India \\ sparchani@yahoo.com
}

\begin{abstract}
Since Partition, the Sindhi language in India has frequently been written off by scholars and laypersons alike, citing supposed linguistic corruption, ever-shrinking domains of use, and near-obsolescence in written form. However, census figures have consistently registered an increase in Sindhi speakers in India over the last seven decades. This article argues for a fresh approach to analyzing the journey of Sindhi in post-Partition India to explain this apparent discrepancy. It adopts a language-ecological perspective and evaluates salient grammatical, sociolinguistic, and script-related changes in Indian Sindhi over the last seventy-five years. The article maintains that these changes represent structurally and sociolinguistically plausible adaptations to the language's ecosystem since Partition. It concludes that, despite a reduction in domains of use, changes in Indian Sindhi, together with an increase in speakers, testify to the language's survival in India.
\end{abstract}

\section{Keywords}

Indian Sindhi - sociolinguistics - language contact - language ecology 
Following the 1947 Partition of British India and the arrival of nearly eight hundred thousand refugees from Sindh in what became independent India, much has been said, written, and debated on the state and fate of the Sindhi language in the country. Overall, prognoses on the future of the language in India have routinely painted a bleak picture. Such pessimism appears to hinge on a perceived decline or decay in three distinct language domains: structural purity, function in society, and conspicuousness in everyday life. Structurally, Sindhi in India has undergone well-documented changes in its sound system, grammar, and vocabulary. Members of the Indian Sindhi community, especially seniors, have disapproved of many of these structural changes. In terms of function, Sindhi in post-Partition India has seen a starkly reduced functional load. People almost never use it for administrative or other official purposes anywhere in India. It is also generally not preferred as a medium of education by the community and restricted mainly to informal oral use in familial and community domains. Probably most symbolic of the language's apparent loss in status is its ever-diminishing presence in written form. Since Partition, a yetunresolved and contentious script debate has also negatively impacted Sindhi in India.

Public discourse on the future of Sindhi in India often betrays the anxiety on this matter felt within the community, especially by older members. At times, this anxiety manifests in the form of appeals by prominent Indian Sindhi personalities calling on community members to keep their heritage language alive. For instance, acclaimed lawyer and politician Ram Jethmalani (1923-2019) has gone on record declaring that:

[T] he only testament to sindhyata [Sindhiness] is the Sindhi language. If the Sindhi language vanishes, both sindhyata and Sindhis would fundamentally cease to exist. ${ }^{1}$

Revered spiritual leader Jashan P. Vaswani (1918-2018), popularly referred to by the Sindhi honorific dada or "elder brother," echoed a similar sentiment. Dada Jashan would regularly beseech his audiences to speak Sindhi amongst themselves, especially with children, to ensure the language's continuity. On occasion, he would intersperse his pleas with regret at the state of the language in India:

1 "Ram Jethmalani Conversation with Kamlesh Moorjani \& Asha Chand," YouTube video, 8:59, posted by "Sindhi Sangat," December 2013 (https://youtu.be/KndGIASZPb8 [accessed March 16, 2021]). The quotation appears from o:38 to o:52. The translation is ours. 
It saddens me that, of all the hundreds of thousands of nations and communities worldwide, the Sindhi community is unique in not having that love of one's language. ${ }^{2}$

Such an ominous outlook on Sindhi's future in India is not restricted to lay community opinion. A similar subtext is also found in scholarly analyses of the phenomenon by senior academics. For instance, linguist Chander Daswani opines that Sindhi "has no future in India and that it will ultimately decay and die." ${ }^{3}$ Along similar lines, educationist Subhadra Anand believes that Sindhi in India is "facing a situation of near extinction."4 Against this background, one can forgive anyone for thinking that the Sindhi language in India has undergone an irreversible decline, is moribund, and is on the verge of dying out.

\section{$2 \quad$ The Decline of Sindhi in India?}

Viewed against the background of the oldest generation of Indian Sindhis' firsthand experiences of Partition and upheaval, their emotional angst on matters of heritage language is valid and understandable. Accordingly, this generation's use of the word "decline" to describe the status and future of Sindhi in India appears colored by sentimentality. It is necessary to acknowledge and validate this emotion. However, it is also imperative to counterbalance qualitative descriptions of sociolinguistic phenomena with quantitative data to arrive at a holistic view.

In this regard, looking at quantitative data on Sindhi in India does prove revealing and thought-provoking. What seems to have slipped between the cracks and largely bypassed popular perception and scholarly scrutiny is that Indian census figures on the number of Sindhi speakers have consistently contradicted the widely held belief of the language's decline in the country. After the first post-Partition Indian census in 1951, every subsequent decennial census has registered a steady increase in the number of self-reported Sindhi mother-tongue speakers. These figures are in Table 1.

2 "Dada J.P.Vaswani Talk about the Sindhi Language," YouTube video, 8:42, posted by Sindhhala, January 2012 (https://youtu.be/ujCJ99A4zsU [accessed March 16, 2021]). The quotation appears from $5: 24$ to $5: 53$. The translation is ours.

3 Chander Daswani, "Multilingualism and Language Decay: The Case of Indian Sindhi," International Journal of the Sociology of Language 75 (1989): 59 .

4 Subhadra Anand, National Integration of Sindhis (Mumbai: Vikas Publishing House, 1996), xiii. 
TABLE 1 Census figures for Sindhi speakers in India

\begin{tabular}{lr} 
Census year & Sindhi spe \\
\hline $1947 / 48$ (after Partition) & 776,029 \\
1951 & $1,250,000$ \\
1961 & $1,371,932$ \\
1971 & $1,676,875$ \\
1981 & $2,044,389$ \\
1991 & $2,122,848$ \\
2001 & $2,535,485$ \\
2011 & $2,772,264$
\end{tabular}

CHANDER DASWANI AND SUNDRI PARCHANI, SOCIOLINGUISTIC SURVEY OF INDIAN SINDHI (MYSORE: CENTRAL INSTITUTE OF INDIAN LANGUAGES, 1978), 5; "ABSTRACT OF SPEAKERS' STRENGTH OF LANGUAGES AND MOTHER TONGUES - 2011," OFFICE OF THE REGISTRAR GENERAL AND CENSUS COMMISSIONER (HTTPS://WWW.CENSUSINDIA.GOV. IN/2011CENSUS/LANGUAGE-2011/STATEMENT-1.PDF [ACCESSED MARCH 16, 2021]).

These figures conflict with the ubiquitous and pessimistic forecasts about Sindhi's future in India. To wit, what strikes one as defying the odds is not just the persistence of Sindhi in post-Partition India. Instead, it is the consistent growth in the language's speaker base in the country for close to seven-anda-half decades following Partition. These data prompt further scrutiny of existing analyses of Sindhi in post-Partition India, starting with our conceptualization of language shift. Traditionally, language shift in the scholarly literature is characterized as a more-or-less simultaneous decrease in a language's domains of use, speaker base, and ethnolinguistic affiliation. ${ }^{5}$ It follows that a situation where there is no attested decrease in one or more of these criteria presents a definitional problem: to what extent can such a situation be reasonably labeled language shift? In post-Partition India, there is a consensus among academics that Sindhi's domains of use have reduced. In terms of speaker numbers, though, census figures in Table 1 leave no doubt on the increase therein. Findings on ethnolinguistic affiliation with Sindhi are somewhat equivocal, with different scholars reporting negative, neutral, or even positive community attitudes towards the language. That said, it is conceivable that the census figures in Table 1 may well include individuals who claim

5 Joshua A. Fishman, Reversing Language Shift: Theory and Practice of Assistance to Threatened Languages (Clevedon: Multilingual Matters, 1991). 
Sindhi as their mother tongue despite limited fluency in it. This possibility points toward a nominally positive (or, at least, not negative) attitude toward the ethnolinguistic label of "Sindhi."

Against this background, adopting traditional definitions of language shift to describe the situation of Sindhi in India may paint an incomplete or even misleading picture. Indeed, the decrease in domains of use with a simultaneous increase in speaker numbers points to, if not the vitality, then at least the durability of Sindhi in independent India. Put differently, Sindhi in postPartition India may not have thrived, but it has survived. This fact highlights the need to revisit and use a different lens to view Sindhi's presence in India over the last seventy-five years.

Accordingly, we contend in this article that there exists a need for a fresh approach to critiquing and comprehending the journey and the present-day reality of the Sindhi language in independent India - indeed, the life and times of Sindhi in India nearly seventy-five years after Partition. The article eschews the paradigm of language shift and returns to basics. It asks why and how Sindhi has resisted extinction and survived in the dense and diverse Indian linguistic ecosystem. To answer these questions, the article draws on and synthesizes data from sociolinguistic studies on Indian Sindhi conducted over the past sixty years. These studies show that Sindhi has endured in post-Partition India because of its ability to adapt, blend, and find a niche in the environment. Paradoxically, this environmental adaptation has resulted in Sindhi becoming unseen, causing a reduction in domains of use. The article concludes that, despite diminishing societal visibility, Sindhi's adaptation to the Indian linguistic ecosystem should not be viewed as decay or loss. Instead, it is better understood as the language's sociolinguistic integration with its surroundings, which has ensured its continuity in India for more than seven decades.

\section{Towards a Fresh Perspective: Ecology, Adaptation, and Survival}

While the census figures in Table 1 illustrate the survival and nominal growth of Sindhi in India, they do not shed light on why or how this has occurred. To find these answers, a theoretical paradigm that appears promising at first glance is the variationist approach, pioneered by linguist William Labov in the 1970s. ${ }^{6}$ Under the variationist approach, specific changes identified in a language's form are measured in terms of their frequency of occurrence in

6 Sali A. Tagliamonte, Variationist Sociolinguistics: Change, Observation, Interpretation (Chichester: Wiley-Blackwell, 2012). 
each data corpus and analyzed for the likely environmental factors motivating them. However, the changes observed and documented in Indian Sindhi go beyond the language's form and extend to its function and presence in society. To suitably account for these changes, we propose instead an approach grounded in the principles of language ecology as pioneered by linguist Einar Haugen. ${ }^{7}$ Haugen defines language ecology as:

$[\mathrm{T}]$ he study of interactions between any given language and its environment ... the true environment of a language is the society that uses it as one of its codes. ${ }^{8}$

In Haugen's approach, language is implicitly an "organism," attempting to adapt to its environment in ways that ensure its survival. This approach includes navigating its place among the other organism-like languages that share a common space and compete for space within it. According to ecolinguists Salikoko Mufwene and Cécile Vigouroux, such an approach may illuminate how:

[D]ifferences in local ecologies can explain, for instance, how a language can prevail in one setting but not in another; why a population in one setting shifted away from their heritage language to embrace another, while another population in a seemingly similar situation did not adapt the same way to a similar ecology; and why a language has remained structurally closer to its ancestor in the mother-land in one setting but not in another. ${ }^{9}$

Adopting this approach also has precedent in the context of South Asian minority multilingualism. To account for intergenerational multilingualism among minority-language speakers in India, Ajit Mohanty adopts a similar approach. Mohanty describes the phenomenon using the term "anti-predatory" behavior:

When animals of subordinate species are threatened by powerful predators, they engage in some anti-predatory behaviors to enhance their chances of survival. Such behaviors usually involve retreating to areas of

7 Einar Haugen, The Ecology of Language (Stanford, CA: Stanford University Press, 1972). For the sake of simplicity, we treat the terms ecology and ecosystem as effectively equivalent in the present context and use them interchangeably.

8 Haugen, 323 .

9 Salikoko S. Mufwene and Cécile B. Vigouroux, "Individuals, Populations, and Timespace: Perspectives on the Ecology of Language Revisited," Language Ecology 1.1 (2017): 76 (https:// benjamins.com/catalog/le.1.1.o5muf [accessed March 16, 2021]). 
lesser access and visibility and low resources. A similar pattern is quite evident in the maintenance of minor and tribal languages in contact with major languages in India. In face of pressures from dominant contact languages, these languages withdraw into domains of lesser socio-economic power and significance and their speakers usually adopt a form of bilingualism in which the tribal/minority languages are invariably restricted to domains of home and in-group communication and other less significant domains. ${ }^{10}$

Admittedly, the characterization of human language as an organism implicitly ascribes to it a degree of agency and volition that sits uneasily with the fact - or truism - that language is inanimate. Notwithstanding this ontological contradiction, it is also evident that such a characterization can prove advantageous in critically analyzing the distribution and survival of languages in a particular "habitat." Consequently, this article adopts Haugen's and Mufwene's invocation of ecology to explain language change and couples it with Mohanty's analogy of anti-predatory behavior to allegorically yet rigorously explain how Sindhi has successfully survived in the Indian language ecology for several decades after Partition. ${ }^{11}$

That said, a rigorous analysis requires a suitable theoretical approach and reliable and fit-for-purpose data. In the present context, this refers to data demonstrating how Sindhi in post-Partition India has gradually changed in terms of form, function, and presence to blend into its transplanted habitat. Fortunately, the last six decades have seen four significant linguistic studies focusing on Sindhi in India, carried out at regular intervals:

$10 \quad$ Ajit K. Mohanty, "Multilingualism of the Unequals and Predicaments of Education in India: Mother tongue or Other Tongue?," in Imagining Multilingual Schools: Language in Education and Glocalization, eds. Ofelia García, Tove Skutnabb-Kangas and María E. Torres-Guzmán (Clevedon: Multilingual Matters, 2006), 266.

11 In recent times, the link between environment and language structure has received particular attention thanks to an article by psychologists Gary Lupyan and Rick Dale, who conclude: "Just as biological organisms are shaped by ecological niches, language structures appear to adapt to the environment (niche) in which they are being learned and used" (Gary Lupyan and Rick Dale, "Language Structure Is Partly Determined by Social Structure," PLOS ONE 5.1 (2010): 1 (https://doi.org/10.1371/journal.pone.ooo8559 [accessed March 16, 2021])). However, given Lupyan and Dale's statistical-quantitative approach antithetical to the qualitative one we adopt, we refrain from invoking their work in greater detail. 
1. "The Acculturation of Indian Sindhi to Hindi" by Lachman Khubchandani. ${ }^{12}$ Based on Haugen's theory of linguistic acculturation, the dissertation describes changes in the sound system, vocabulary, and, to a lesser extent, the sociolinguistics of Sindhi in India roughly fifteen years after Partition.

2. Sociolinguistic Survey of Indian Sindhi by Chander Daswani and Sundri Parchani. ${ }^{13}$ Conducted roughly three decades after Partition in 1975, this remains to date the most comprehensive sociolinguistic study on the use of, competence in, and attitudes towards Sindhi in India.

3. "Changes in Sindhi in the Indian Context" by Sundri Parchani.14 This paper is a compilation of two follow-up case studies to the Sociolinguistic Survey conducted by Daswani and Parchani between 1977 and 1982, focusing primarily on changes in the sound system and grammar of Indian Sindhi.

4. "Sindhī Multiscriptality, Past and Present" by Arvind Iyengar. ${ }^{15}$ This doctoral dissertation investigates the use of, and attitudes towards, various scripts for the Sindhi language in the Indian and diasporic context. It includes research collected over the period 2014-2015, nearly seventy years after Partition.

Also, deserving mention here is the monograph Sindhi Bolia ain Adaba ji Tarikha (A History of the Sindhi Language and its Literature) by grammarian and lexicographer Kanhaiyalal Lekhwani. ${ }^{16}$ Despite focusing primarily on Sindhi literature, Lekhwani's work corroborates several of the conclusions drawn by the above linguistic studies.

Besides documenting and describing the changes in Indian Sindhi's sound system, grammar, vocabulary, function in society, and written characteristics over the years, the four studies mentioned above also investigate the likely factors behind said changes. This fact makes them particularly suited to address why and how Sindhi has survived in the country. The following sections draw

12 Lachman M. Khubchandani, "The Acculturation of Indian Sindhi to Hindi: A Study of Language in Contact," Ph.D. diss., University of Pennsylvania, 1963 (http://repository .upenn.edu/dissertations/AAI64O738o [accessed March 16, 2021]).

13 Chander Daswani and Sundri Parchani, Sociolinguistic Survey of Indian Sindhi (Mysore: Central Institute of Indian Languages, 1978).

14 Sundri Parchani, "Changes in Sindhi in the Indian Context," a paper presented at the Sindhi Academy, Delhi (June 20, 1998).

15 Arvind V. Iyengar, "Sindhī Multiscriptality, Past and Present: A Sociolinguistic Investigation into Community Acceptance," Ph.D. diss., University of New England, 2017 (https://rune .une.edu.au/web/handle/1959.11/22722 [accessed March 16, 2021]).

16 Kanhaiyalal Lekhwani, Sindhi Bolia ain Adaba ji Tarikha (Mysore: Central Institute of Indian Languages, 2011). 
on these studies to synthesize, analyze, and discuss the changes in Indian Sindhi and the factors behind them, using a language-ecological approach.

\section{$4 \quad$ Sindhi in Post-Partition India: Adaptation and Adaptability}

To make the content in this article accessible to the broadest possible audience, we have consciously avoided using the International Phonetic Alphabet to transcribe Sindhi-language data. Instead, we use a Roman transliteration system based on the one used for Sindhi in the monumental Linguistic Survey of India (1919). This transliteration system aligns with other systems, such as the International Alphabet for Sanskrit Transliteration (IAST). It should be self-explanatory to anyone reasonably proficient in a modern Indo-Aryan language. Because this article has a sociolinguistic focus, its use of transliteration instead of phonetic transcription in no way compromises its analysis. We do, however, retain the following linguistic conventions in our transliteration:

- Symbols enclosed in slashes depict the underlying sound units or phonemes in the language in question, e.g., Sindhi /b̈akiri// "she-goat," featuring the characteristic Sindhi implosive / $/$ / (see section Consonants).

- Symbols enclosed in square brackets represent the pronunciation or phonetic realizations of sound units and words, e.g. [bakirī], with $/ \ddot{b} /$ replaced by $[\mathrm{b}]$.

- Symbols enclosed in angle brackets represent the orthographic or written forms of sound units and words, e.g., 〈bakirī $\rangle$.

\subsection{Form}

The sound system (i.e., phonology) of Sindhi has been the focus of scholarly study since the mid-nineteenth century, before the establishment of modern linguistics as a discipline. ${ }^{17}$ Despite this, experts disagree on the exact nature and number of sound units - or phonemes - in modern Sindhi. The disagreement has been further exacerbated by changes in Indian Sindhi's sound system in the post-Partition era, resulting in a divergence from Pakistani Sindhi. These changes are described below.

17 George Stack, A Grammar of the Sindhi Language (Bombay: American Mission Press, 1849), 1-10. Stack was not a linguist, but a colonial administrator. Also, he wrote his grammar in an era before the advent of modern phonetic analysis. Conseqeuntly, Stack fails to clearly distinguish between letters and sounds in his work. Despite this, his analysis reveals a deep understanding of the Sindhi sound system and offers a snapshot of Sindhi as spoken in the mid-nineteenth century. Hence, from a historical-linguistic perspective, Stack's work remains invaluable. 


\subsection{Consonants}

Table 2 shows the inventory of consonant phonemes in standard Sindhi as generally accepted by contemporary scholars.

Since 1947, there have been two significant consonantal transformations observed and documented in Indian Sindhi. Both transformations can be partly attributed to the influence of the linguistic environment. The first transformation involves the four consonants / $\mathrm{k}_{\underline{h}} \mathrm{~g} \underline{\mathrm{h}} \mathrm{z} \mathrm{f} /$, which emerged in Sindhi due to Persian and Arabic influence. In his pioneering Sindhi grammar of 1872, the German Christian missionary Ernst Trumpp writes that "only the Mullās, who pretend to a knowledge of Arabic, affect the deep guttural articulation of the Arabic [for these four consonants]." ${ }^{18}$ According to Trumpp, the average

TABLE 2 Inventory of consonants in standard Sindhi

\begin{tabular}{|c|c|c|c|c|c|c|c|c|c|}
\hline \multirow{3}{*}{ Plosive } & \multicolumn{2}{|c|}{ Labial } & Dental & Alveolar & Retroflex & Palatal & \multicolumn{2}{|c|}{ Velar } & \multirow[t]{3}{*}{ Glottal } \\
\hline & $\mathrm{p}$ & $\mathrm{b}$ & $\mathrm{t} \quad \mathrm{d}$ & & $\mathrm{t}$ & & $\mathrm{k}$ & $\mathrm{g}$ & \\
\hline & ph & bh & th $\mathrm{dh}$ & & țh ḍh & & $\mathrm{kh}$ & gh & \\
\hline Implosive & $\ddot{\mathrm{b}}$ & & & $\ddot{\mathrm{d}}$ & & $\ddot{j}$ & & $\ddot{\mathrm{g}}$ & \\
\hline Nasal & & $\mathrm{m}$ & & $\mathrm{n}$ & ṇ & $\tilde{n}$ & & $\dot{\mathrm{n}}$ & \\
\hline Affricate & & & & & & $\begin{array}{ll}\text { ch } & j \\
\text { chh } & \text { jh }\end{array}$ & & & \\
\hline Fricative & $\mathrm{f}$ & & & $\mathrm{z}$ & & sh & $(\mathrm{kh}$ & gh) & $\mathrm{h}$ \\
\hline Approximant & & $\mathrm{v}$ & & & & $\mathrm{y}$ & & & \\
\hline Tap/Flap & & & & $\mathrm{r}$ & $\stackrel{r}{r} \quad \underline{r h}$ & & & & \\
\hline Lateral & & & & 1 & & & & & \\
\hline
\end{tabular}

JENNIFER S. COLE, "SINDHI," IN ENCYCLOPEDIA OF LANGUAGE \& LINGUISTICS (SECOND EDITION), ED. KEITH BROWN (OXFORD: ELSEVIER, 2006), 385.

18 Ernst Trumpp, Grammar of the Sindhi Language: Compared with the Sanskrit-Prakrit and the Cognate Indian Vernaculars. (Leipzig: F.A. Brockhaus, 1872), 20. 
Sindhi speaker, whether Muslim or Hindu, would usually render these conso-

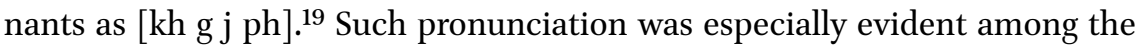
illiterate, who comprised the majority of the population at the time. ${ }^{20}$

By the mid-twentieth century, though, increasing language standardization and mass education in Sindh had resulted in / $\mathrm{kh}$ gh $\mathrm{z}$ f/ becoming established in spoken Sindhi. In "Acculturation," Khubchandani notes that articulating these consonants as [kh g j ph], respectively, was seen as unrefined..$^{21}$ However, Partition set into motion the loss of $/ \mathrm{kh}$ gh $/$ from the speech of Indian Sindhis. Khubchandani attests to the beginnings of this shift in observing that, shortly after Partition, even Sindhi-educated individuals at the time were prone to pronouncing $/ \mathrm{kh}$ gh $/$ as $[\mathrm{kh} \mathrm{g}]$, respectively, with $/ \mathrm{g} \underline{\mathrm{h}} / \rightarrow[\mathrm{g}]$ being particularly evident. Parchani reports that by the early $1980 \mathrm{~s}, / \mathrm{k} \underline{\mathrm{h}} \mathrm{g} \underline{\mathrm{h}} / \mathrm{were}$ being rendered identically to $[\mathrm{kh} \mathrm{g}]$, respectively, to the extent that scholars questioned the independent status of / $\mathrm{kh} \mathrm{gh} /$ in Sindhi's sound system. ${ }^{22}$ Phonetician Paroo Nihalani's observation backs up Parchani's claim in the late 1970s that $/ \mathrm{k} \underline{\mathbf{h}} \mathrm{gh} /$ had, "for all practical purposes, disappeared from the speech of the younger generation." ${ }^{33}$ Iyengar in "Sindhī Multiscriptality" observes that this consonant merger has resulted in unintentional homophones, as in /sakhī/ "female friend" and /sakhīi/ "generous" both realized as [sakhī]. ${ }^{24}$ In contrast, /z f/ seem more stable in the sound system of Indian Sindhi. Lekhwani notes that, of the four consonants, only / $\mathrm{z}$ f/ continue to be clearly articulated in contemporary Indian Sindhi. ${ }^{25}$ Iyengar ascribes the persistence of these two consonants in Indian Sindhi to the reinforcing effect of English, which is a language many younger Indian Sindhis are familiar with and whose sound system features $/ \mathrm{zf} / .^{26}$

The second significant transformation in Indian Sindhi since Partition is the loss of implosive consonant sounds / $\ddot{\mathrm{g}} \mathrm{j} \ddot{\mathrm{d}} \mathrm{b} /$. Phonetically, implosives are sounds produced by sucking air into the lungs as opposed to the more

19 Ibid., 20-21.

20 Citing government figures, lyengar writes that "[a]s of 1901, the literacy rate in Sindh was 9.3 percent for Hindūs, and o.74 percent for Muslims" ("Sindhī Multiscriptality," 124).

21 Khubchandani, "Acculturation," 256.

22 Parchani, 19.

23 Paroo K. Nihalani, "The Phonetics of Sindhi," Ph.D. diss., University of Edinburgh, 1978, (http://hdl.handle.net/1842/18493 [accessed March 16, 2021]), 2-3.

24 Iyengar, "Sindhī Multiscriptality," 43-44. In Dama Dam Mast Qalandar, a popular song among Sindhis, the lyrics /sakhī shahbāz qalandar/, which feature $/ \mathrm{kh} /, / \mathrm{z} /$, and the Arabic-origin consonant /q/, may well act as a makeshift shibboleth to distinguish a contemporary Indian speaker from a Pakistani one. See also footnotes 35 and 38 .

25 Lekhwani, 34 .

26 Iyengar, "Sindhī Multiscriptality," 43-44. 
common plosives produced by expelling air from the lungs. ${ }^{27}$ Despite the four implosives being emblematic of Sindhi, they have been steadily disappearing in the post-Partition Indian variety of the language. In "Acculturation," Khubchandani makes no mention of the implosives becoming unstable in Indian Sindhi. However, less than twenty years later, Parchani describes them being predictably replaced by the corresponding plosives $/ \mathrm{g} \mathrm{j} \mathrm{d} \mathrm{b} /$ in the speech of Sindhi speakers under thirty-five years old. ${ }^{28}$ Three decades later, Lekhwani affirms Parchani's observation. Lekhwani writes that children in Sindhi families outside of a comprehensive Sindhi-speaking milieu are typically unable to articulate the implosives. ${ }^{29}$

Both these consonantal transformations, namely, the disappearance or instability of $/ \mathrm{kh}$ gh z f/ and /g̈ $\ddot{\mathrm{d}} \ddot{\mathrm{b}} /$, are not unusual given the language ecosystem that Sindhi finds itself in India. The consistent rendering of /kh gh z f/ as [kh g j ph], respectively, has also been attested in Hindi, a language many Indian Sindhis are bilingual in. ${ }^{30}$ In addition, the implosives / $\ddot{\mathrm{g}} \mathrm{j} \ddot{\mathrm{d}} \mathrm{b} /$ among modern Indo-Aryan languages are primarily restricted to Sindhi and southern Panjabi (also called Siraiki). ${ }^{31}$ Therefore, the restricted occurrence of the implosives makes them prone to being shed in the face of sustained contact with unrelated languages. Indeed, even Sindhi varieties that have had extensive contact with implosive-less Indo-Aryan languages feature a reduced set of implosives, as seen in Kachchhi. ${ }^{32}$

The consonantal transformations in question go beyond simple instances of cause-and-consequence and carry sociolinguistic significance. In the broader context of present-day India, sociolinguist Rizwan Ahmad argues that the pronunciations / kh gh z f/ indicate "Urdu" speech and, by extension, the speaker being "Muslim." In contrast, pronouncing the consonants as [kh gj ph] is indexical of "Hindi" speech and, consequently, the speaker's likely "Hindu" identity. ${ }^{33}$ The variable pronunciation of $/ \mathrm{kh}$ gh z f/, thus, collectively

27 For an acoustic-phonetic analysis of Sindhi implosives, see Nihalani, "The Phonetics of Sindhi."

28 Parchani, 19.

29 Lekhwani, 34.

$30 \quad$ Michael C. Shapiro, "Hindi," in The Indo-Aryan Languages, eds. George Cardona and Dhanesh Jain (London: Routledge, 2007), 286-287.

$31 \quad$ Christopher Shackle, "Panjabi," in The Indo-Aryan Languages, eds. George Cardona and Dhanesh Jain (London: Routledge, 2007), 646-647.

32 Lachman M. Khubchandani, "Sindhi," The Indo-Aryan Languages, eds. George Cardona and Dhanesh Jain (London: Routledge, 2007), 690.

33 Rizwan Ahmad, "Unpacking indexicality: Urdu in India," Texas Linguistic Forum 52 (2008): 1-9 (http://rizwanahmad.org/wp-content/uploads/2013/12/Ahmad-20o8b.pdf [accessed March 16, 2021]). In his list of sociolinguistically indexical phonemes, Ahmad includes 
acts as a sociolinguistic variable that, in the popular imagination, may subconsciously paint the speaker in religious overtones. ${ }^{34}$ Linguist Braj Kachru alludes to a similar dichotomy in Kashmiri based on one's articulation of / k $\mathrm{gh} \mathrm{f} /$, although he is at pains to not frame this phonological phenomenon as a Muslim-Hindu dialectal dichotomy. ${ }^{35}$ In the context of contemporary Sindhi, the articulation of the consonants in question as $/ \mathrm{kh} \mathrm{gh} \mathrm{z} \mathrm{f} /$ on the one hand, or as [kh g j ph] on the other, might similarly index the speaker's background as "Muslim" or "Hindu" and, consequently, as Pakistani or Indian, respectively. ${ }^{36}$ Depending on the social context, such implicit identification may have positive or negative consequences for the speaker.

Similar to /kh gh $\mathrm{z} f /$ functioning as a variable carrying implications of identity, the four Sindhi implosives /g̈ j $\ddot{\mathrm{d}} \ddot{\mathrm{b}} /$ also collectively act as a variable. In popular perception, this variable may index the authenticity of one's Sindhi and, by extension, their proficiency in the language. In "Sindhī Multiscriptality," Iyengar quotes an elderly study participant who disapproves of the Sindhi word /bakirī/ "she-goat" being articulated as [bakirī]. For this fluent Sindhi speaker, replacing implosive $/ \ddot{b} /$ with plosive $[\mathrm{b}]$ is a sign of inadequate

/q/, which is an established sound in Urdu. In Sindhi, however, its status is unclear. Khubchandani opines that /q/ does not exist per se in Indian Sindhi ("Acculturation," 263). In contrast, Jennifer Cole states that Urdu influence has reinforced /q/ in contemporary Pakistani Sindhi, especially in the speech of urban, educated Sindhi-Urdu bilinguals (385).

34 Michel Boivin, "Islam, Langues et Identités Régionales dans l'Inde Coloniale : l'Exemple du Sindh (1851-1939)," Revue des Mondes =Musulmanes et de la Méditerranée 124 (2008): online (https://journals.openedition.org/remmm/6o14 [accessed March 16, 2021]). Boivin writes that " $[\mathrm{t}]$ he distinct identity of Urdu as the language of Muslims hinged on its Arabo-Persian vocabulary, contrasted with Hindi's Sanskrit-origin terminology (translation ours)." What Boivin describes is the lexical parallel to the phonological phenomenon we describe.

35 Braj B. Kachru, An Introduction to Spoken Kashmiri (Urbana, IL: University of Illinois, 1973): $7-11$.

36 While older Indian Sindhis may continue to articulate / $\mathrm{k} \underline{h} /$ as such, impressionistic observations suggest that the phonetic quality of such sounds may differ from their Pakistani counterparts. In a Sindhi-language interview featuring senior intellectuals from both sides of the border, the Indian host Ram Jawhrani is heard uttering the word /khālu/ "vacuum" at 1:04, followed by the Pakistani guest Anwar Pirzado saying /khyāla/ "opinion" at 7:54. In both words, both speakers enunciate the phoneme $/ \mathrm{kh} /$. However, the articulations differ in acoustic intensity, with Jawhrani's articulation subdued and Pirzado's prominent. These distinct pronunciations of the same sound unit are worthy of further phonetic and sociolinguistic examination ("Sahyog Foundation; 'Sindhi Sarvech' ANWAR PIRZADO \& GULAM NABI CHANDIO, by Dr. Ram Jawhrani," YouTube video, 25:31, posted by "Sahyog Foundation," January 2016 (https://youtu.be/uCviTIIgYao [accessed March 16, 2021]). 
Sindhi proficiency. ${ }^{37}$ Nevertheless, Iyengar also quotes other elderly Sindhis who are neutral to the disappearance of implosive sounds and the obsolescence of the corresponding letters from the written form. Such speakers welcome a simplified linguistic structure if it aids in the survival of the language in India. ${ }^{38}$

\subsection{Vowels}

Historically, Sindhi words of all parts of speech have tended to end in a vowel. When borrowing a foreign word ending in a consonant, Sindhi usually appends it with one of the short vowels /aiu/, based on vowel harmony or other factors. ${ }^{39}$ In pre-Partition Sindh, the existence of a comprehensive Sindhi-speaking environment helped maintain the linguistic feature of vowel-finality. However, following Partition and transplantation of the language in India, this phonological feature began to unravel. Given that most major Indo-Aryan languages do not require words to be vowel-final, Sindhi has steadily been undergoing contact-based change to permit consonant-final words. Unsurprisingly, this phenomenon was first observed on yet-to-be-assimilated loanwords. In "Acculturation," Khubchandani notes that "it is a growing tendency to retain $\mathrm{H}$ [indi] consonant endings in S[indhi]." 40 Fifty years on, Lekhwani confirms the phenomenon, adding that it has now spread to native Sindhi vocabulary.41

When writing this article, there was no comprehensive study available of Sindhi as spoken in southern India, where the major languages in the surrounding linguistic ecosystem belong to the Dravidian language family and favor vowel-finality. ${ }^{42}$ A descriptive-sociolinguistic study of Sindhi as spoken in southern Indian cities like Chennai (formerly Madras) and Bengaluru (formerly Bangalore), where Sindhi populations have been present since Partition, would be a welcome addition to the body of knowledge.

Another vowel-related phonetic feature that has gradually disappeared in Indian Sindhi is the nasalization of final vowels in specific female names. In "Acculturation," Khubchandani notes that Sindhi names for women like /lilẫ/ "Lila" and /mīrã̃/ "Mira" continue to be distinguished from their Hindi counterparts by the nasalization of the final vowel. However, he also surmises that

37 Iyengar, "Sindhī Multiscriptality," 178.

38 Ibid., 172-173.

39 Trumpp, 88-98.

$40 \quad$ Khubchandani, "Acculturation," 266.

41 Lekhwani, 34.

42 Bhadriraju Krishnamurti, The Dravidian Languages (New York: Cambridge University Press, 2003). 
this phonetic feature may be indicative of an older pronunciation. ${ }^{43}$ Twenty years on, Parchani affirms that younger Sindhi speakers pronounce such personal names with the final vowel not nasalized, in line with their usual Hindi pronunciation. ${ }^{44}$ The gradual loss of nasalization in female personal names can be indirectly attested in different scripts' orthographies. For instance, a publication by the spiritual sect Radha Soami Satsang, Beas on the sixteenth-century Bhakti mystic Mirabai spells her name in Perso-Arabic Sindhi as ميران $\langle$ mirã̃ $\rangle$, reflecting the traditional spelling that features wordfinal nasalization. ${ }^{45}$ Given the spiritual theme of the publication and its utilization of the Perso-Arabic script, it is reasonable to assume that the authors and target audience are older community members. In contrast, the eponymous St. Mira's educational institutes in Pune, ostensibly oriented towards English-speaking parents and children, do not indicate nasalization in the Roman-script spelling of their patron saint's name. ${ }^{46}$

From a phonological perspective, sustained contact with distinct languages and the absence of a comprehensive Sindhi-speaking environment, have apparently triggered a harmonization of Indian Sindhi's sound system with surrounding languages. However, such sound changes come with pragmatic, grammatical, and sociolinguistic implications, sometimes resulting in a Catch22. If speakers do not clearly articulate the implosives or word-final vowels, older speakers may deem such Sindhi speech "corrupted" and inauthentic. But if one does pronounce these phonological features clearly, younger speakers may consider it an old-fashioned pronunciation. Children and youngsters may view nasalized final vowels in female personal names as indexing an outdated or even geriatric "accent" and consider such pronunciations a source of amusement. Lekhwani also reports that the loss of grammatically salient word-final vowels (e.g., /gharu/ "house," /ghara/ "houses," and /ghari/ "in the house" all rendered [ghar]) has pedagogical implications for lexicography and language teaching. ${ }^{47}$ Iyengar echoes this sentiment in noting that such sound changes have effectively created a generational divide in Indian Sindhi pronunciation,

\footnotetext{
43 Khubchandani, "Acculturation," 206.

44 Parchani, 18.

45 S.L. Sodhi, Mìrã Prem Dìvānī (Amritsar: Radha Soami Satsang, Beas, 1981) (https://archive. org/details/mirapremdiwani/mode/2up [accessed March 16, 2021]).

46 See the institution's website at https://www.stmirascollegepune.edu.in/ [accessed March 16, 2021].

47 Lekhwani, 34.
} 
raising questions of what pronunciation(s) - and, by extension, spelling(s) - to employ in pedagogical contexts. ${ }^{48}$

\subsection{Grammatical Structure}

As shown above, the sound system of Indian Sindhi appears to be steadily reconciling itself with phonological traits commonly found in the Indian linguistic ecosystem, often by sacrificing the very features that distinguish Sindhi from other languages. Likewise, the grammar of Indian Sindhi, too, seems to be dropping distinctive characteristics to blend in. Two manifestations of this process are the loss of pronoun suffixes and changes to the gender of nouns.

Among grammarians and syntacticians, Sindhi is well known for featuring pronoun suffixes. This feature permits a pronoun to be replaced by a suffix tacked onto another word in the clause. Doing so compresses the utterance while preserving its meaning. For instance, / tũhĩjī māu/ "thy mother" can alternatively appear as /māṇhẽ/, with no change in its essence. Similarly, /huna khe cao/ "you tell him/her" may be compressed to /chaosi/. ${ }^{49}$ Khubchandani states that such pronoun suffixes are common in the northwestern languages of the Subcontinent, including Kashmiri and some Iranian languages. ${ }^{50}$ However, and as with the implosive consonants, most languages in the linguistic ecosystem of present-day India do not exhibit the feature of pronoun suffixes. Therefore, it is unsurprising that Indian Sindhi, too, is gradually discarding this feature. In "Acculturation," Khubchandani notes that the use of pronoun suffixes was declining in writing as well as formal spoken Sindhi, albeit continuing unaffected in everyday speech. ${ }^{51}$ However, twenty years later, Parchani observes that such pronoun suffixes were not only absent in the speech of younger Sindhis but were, in fact, unknown to many in the age group. ${ }^{2}$ Parchani's observations are affirmed by Lekhwani approximately three decades on. ${ }^{53}$

Besides encouraging the loss of certain features, language contact and influence from the Indian linguistic ecosystem have also resulted in Indian Sindhi persisting only in modified form. In "Acculturation," Khubchandani notes the "vacillating gender" of some Sindhi nouns with close cognates in Hindi, citing the examples of /kitābu/ "book" and /vishai/ "subject." In terms of grammatical

48 Arvind V. Iyengar, "Variation in Perso-Arabic and Devanāgarī Sindhī Orthographies," Written Language and Literacy 21.2 (2018): 169-197 (https://doi.org/10.1075/wll.ooo14.iye [accessed March 16, 2021]).

49 Parchani, 19.

$50 \quad$ Khubchandani, "Sindhi," 715.

$5^{1} \quad$ Khubchandani, "Acculturation," 266.

52 Parchani, 19.

53 Lekhwani, 35 . 
gender, /kitābu/ has traditionally been masculine in Sindhi, and /vishai/ feminine. In contrast, the Hindi cognates of these words are feminine and masculine, respectively. Over time, ecological influence has caused the Sindhi genders of these nouns to align with those of their Hindi counterparts. ${ }^{54}$ In their subsequent studies, Parchani and Lekhwani confirm these drifts in noun gender and note the consequent impact on grammatical rules such as plural formation and adjective agreement. ${ }^{55}$ As with changes in the sound system, changes in grammar, too, often have sociolinguistic implications. For instance, younger Indian Sindhi speakers using Hindi-influenced noun genders may be met with disapproval by older speakers. Changes in noun gender may also result in inflected forms not previously attested, which raises crucial questions for pedagogy.

Widespread disapproval notwithstanding, language change is not a sign of corruption or loss. For instance, in the context of Indigenous Australian languages, where similar grammatical transformations occur, it has been argued that syncretism arising from language contact is not "an indication of a linguistic system unraveling." Instead, such syncretism reflects linguistic systems reorganizing over time due to unavoidable external influence or organic internal evolution. ${ }^{56}$ As demonstrated thus far, this finding is legitimately applicable to Indian Sindhi.

\subsection{Loanwords}

When languages come in contact, the most noticeable impact usually occurs in vocabulary or lexicon. Sindhi is no exception to this rule, and it is indeed the lexicon of Indian Sindhi that reveals the most evident impact of its transplantation in the Indian language ecosystem. It is, therefore, unsurprising that studies over the years have continually affirmed the disproportionate influence of English vocabulary on Sindhi. As eloquently described by Khubchandani in "Acculturation":

A Sindhi speaker is not afraid of mixing Sindhi or English forms while speaking Hindi or Marathi as he does not lose any prestige by showing incomplete acculturation with [the] Hindi or Marathi group, whereas he cannot afford to do so while speaking English, because incomplete access

54 Khubchandani, "Acculturation," 230-235.

55 Lekhwani, 34 .

$5^{6}$ Jackie van den Bos, Felicity Meakins, and Cassandra Algy, "Searching for 'Agent Zero': The Origins of a Relative Case System," Language Ecology 1.1 (2017): 20 (https://doi.org/10.1075/ le.1.1.o2van [accessed March 16, 2019]). 
[to] English detracts from his prestige. There is no demand for exactness of imitation if approximate imitation is rewarding. ${ }^{57}$

In Sociolinguistic Survey, Daswani and Parchani highlight the extent of English influence on Indian Sindhi in noting how English lexicon is being adopted not just for socioculturally novel artifacts (e.g., /blauzu/ "blouse") but also for familiar ones (e.g., /xamīsa/ "shirt" $\rightarrow /$ sharți/). ${ }^{58}$ In line with Khubchandani's observations, Daswani and Parchani attribute such usage to the perceived prestige of English lexical items as an index of the speaker's education or sophistication. By the 2010s, English's influence had resulted in intergenerational language shift away from Sindhi in parts of the community. ${ }^{59}$ However, unlike shifts in language among the Sindhi diaspora in South-East Asia, India's more extensive speaker base seems to have forestalled heritage language shift from becoming pervasive. ${ }^{60}$

After English, it is Hindi that has resulted in the most significant influence on Indian Sindhi. While Hindi has had a considerable impact on the sound system and grammar of Indian Sindhi, its effect on vocabulary is also conspicuous. As with English, Hindi lexical items have, in some instances, displaced native Sindhi terms. However, unlike the ingress of English vocabulary, the adoption of Hindi vocabulary in Sindhi is due less to prestige and more to the currency and circulation of these terms in the linguistic environment. This influence is felt not just on the level of individual words, but also in idiomatic and metaphorical usage. An example is seen in the post-Partition Sindhi coinage /ulūa jo pațho/ "fool," derived from Hindi /ullū kā pațthā/. ${ }^{61}$ Similar is the displacement of the traditional Sindhi proverb /kapirani mẽ na māpanu/ "to be overjoyed" (lit., "to no longer fit in one's clothes") by /phūliyo na samāiṇu/, derived from Hindi / phūle na samānā/ (lit., "to be unable to contain oneself"). ${ }^{62}$

Hindi borrowings are especially pervasive in familial domains. Daswani and Parchani observe that the names of festivals have been undergoing a steady Hindi-ization, such as the Sanskritized [sank(i)rāntī] replacing /tiramurī/,

\footnotetext{
57 Khubchandani, "Acculturation," 45.

58 Daswani and Parchani, 49-51.

59 Arvind V. Iyengar, "Self-Perceptions of Heritage Language Shift among Young Sindhis in Pune," M.A. thesis, University of New England, 2013 (http://dx.doi.org/10.13140/2.1.1769.1841 [accessed March 16, 2021]).

6o Maya Khemlani David, "The Sindhis in Malaysia: Language Maintenance, Language Loss or Language Death?" A paper presented at the International Conference on Bilingualism and National Development, Bandar Seri Begawan, Brunei (December 9-12, 1991).

61 Daswani and Parchani, 58.

62 Lekhwani, 34.
} 
and /rakhị̣i/ by [rakshābandhan(u)].63 Along similar lines, Parchani observes the deprecation of traditional Sindhi kinship terms such as /sauțu/ "father's brother's son," /māroțu/ "mother's brother's son," /māsātu/ "mother's sister's son" and /pūphātu/ "father's sister's son," despite the Sindhi terms being far more precise than their Hindi or English equivalents. ${ }^{64}$

Also influencing Indian Sindhi are regional languages in the Indian linguistic ecosystem, such as Marathi and Gujarati. Regional language loanwords can be sociolinguistically salient and reveal identificational clues. For instance, a Sindhi speaker from Gujarat might substitute traditional Sindhi /thūma/ "garlic" with a form derived from Gujarati /lasan/ "garlic." Similarly, a Sindhi speaker from Maharashtra may replace traditional Sindhi /basaru/ "onion" with Marathi-derived /kāndo/ "onion" (cf. Marathi /kāndā/). Daswani and Parchani provide a comprehensive listing of borrowed and assimilated vocabulary items in Indian Sindhi, which we refer the interested reader to. However, by definition, regional languages lack pan-Indian presence and influence, restricting their usefulness and societal prestige. Furthermore, Marathi and Gujarati speakers tend to use Hindi or English as link languages with Sindhi speakers, especially in urban India, where most Sindhis reside. As a result, the impact of regional languages on Indian Sindhi is restricted compared to that of English and Hindi, causing Sindhi to acquire loanwords primarily from the latter. ${ }^{65}$ From a language-ecological perspective, the higher evolutionary responsiveness, as it were, of Indian Sindhi to English and Hindi than to regional languages is reflective of and proportional to the environmental pressures exerted by the languages in question.

\subsection{Semantic and Pragmatic Shift}

When an organism transplants into a new environment, it may also change its internal workings. Such internal changes can be less conspicuous or evident than external changes. In the context of Indian Sindhi, internal adaptation includes subtle shifts in the meanings and implications of certain words and expressions to align with common practice in the new environment. According to Parmanand Mewaram's now-classic A Sindhi-English Dictionary, the Sindhi noun /vāndho/ stands for "quarrel, uproar," among others. ${ }^{66}$ Roughly

\footnotetext{
63 Daswani and Parchani, 54-55.

64 Parchani, 14. The feminine forms of these kinship terms occur by replacing final /-u/ with /-i/.

65 Khubchandani, "Acculturation," 81.

66 Parmanand Mewaram, A Sindhi-English Dictionary (Hyderabad, Sindh: The Sind Juvenile Co-Operative Society, 1910): 613. Although frequently conflated, Sindhi /vāndho/ is distinct from /vāndo/ "idle, unemployed."
} 
a half-century later, Khubchandani in "Acculturation" glosses /vāndho/ as "concern."67 Yet another half-century later, in his Gujarati-English Learner's Dictionary, Babu Suthar glosses the Gujarati cognate /vāndho/ as "opposition, objection." ${ }^{8}$ In our opinion, Sindhi /vāndho/ has now come to mean the same as its Gujarati counterpart. Tracing the shift in the meaning of this Sindhi word over the last hundred years, thus, reveals a gradual process of "behind-thescenes" adaptation.

A similar process occurs with the Sindhi word /kalha/. Originally meaning "yesterday," the Sindhi word has now acquired the added meaning of "tomorrow" due to influence from Hindi /kal/ "yesterday, tomorrow." In "Acculturation," Khubchandani reports that Sindhi children at the time, including his sister, were starting to use /kalha/ for "tomorrow," instead of the traditional Sindhi /subhāne/.69 Two decades on, Parchani corroborates this change among young Sindhis, especially those living in the strongly Hindi-speaking environment of Delhi. ${ }^{70}$

In certain instances, a word may change meaning purely due to a coincidental phonetic similarity between itself and a similar-sounding word in a neighboring language. For instance, Mewaram, in his Sindhi-English Dictionary, glosses the word /bhulāinu/ in Sindhi as "to mislead, deceive."71 Fifty years on, Khubchandani observes how this word had taken on the additional meaning of "to forget" due to influence from Hindi /bhulānā/ "to forget."72 Since a large section of Khubchandani's work is devoted to this very feature, we refer the reader to the source for further examples.

Also detected in Indian Sindhi are subtle shifts in the insinuations of certain utterances, which proficient language users perceive but elude concrete description. Particularly salient is the pragmatic change in the interjections /are/ and /aṛī, glossed by Mewaram in his dictionary as "Ho! Halloo!"73 Traditionally, Sindhi speakers used these particles when calling out to a lower-status male or female, respectively, lending the particles a pejorative connotation. These particles are considered iconic of Sindhi speech to the

67 Khubchandani, "Acculturation," 81. Khubchandani also insinuates that the word is a loan from Gujarati, which, however, is refuted by the attestation of the word a half-century prior in Mewaram's 1910 Sindhi dictionary.

68 Babu Suthar, Gujarati-English Learner's Dictionary (Philadelphia, PA: University of Pennsylvania) (https://ccat.sas.upenn.edu/plc/gujarati/guj-engdictionary.pdf [accessed March 16, 2021]).

69 Khubchandani, "Acculturation," 239.

70 Parchani, 20.

71 Mewaram, 79.

72 Khubchandani, "Acculturation," 234-235. Compare Sindhi /visāraṇu/ "to forget."

73 Mewaram, 14. 
extent they are often used - or overused - in Indian popular media to stereotype a Sindhi accent. ${ }^{74}$ Despite the particles' salience as a marker of Sindhiness, Daswani and Parchani report a shift in their connotation, from pejorative to nonpejorative, familiar, or even intimate. ${ }^{75}$

\subsection{Function: Other Tongue}

While the ecological pressures exerted by English and Hindi on Indian Sindhi have resulted in adaptations to the structure of Indian Sindhi, they have also resulted in changes to the function and role of Sindhi in the environment. In "Acculturation," Khubchandani notes the abrupt reduction in functional load of Sindhi in its new ecosystem in independent India. The community's commercial and social contact with non-Sindhi speakers, the availability of entertainment and media mostly in other languages, and the perceived need and consequent influence of English and Hindi have resulted in Sindhi being displaced by other languages, particularly in non-familial domains.

Daswani and Parchani corroborate Khubchandani's observations by citing community members' desire to send their children to English-medium schools. The authors attribute this desire to the community's "utilitarian outlook." More importantly, the authors allude to community opinion that Sindhi in India would survive, even in the absence of education in the language, if spoken within the home. ${ }^{76}$ It does appear that, despite going relatively unnoticed in the academic or popular literature, such implicit community confidence in the durability of Sindhi is borne out in the continued presence and steady growth of the language in India three-quarters of a century after Partition.

\subsection{What's in a Name?}

Despite latent community confidence in the language's durability, it is undeniable that overt and covert discrimination experienced by Sindhis in post-Partition India would have impacted their desire or ability to identify as Sindhis openly. A well-attested consequence of such bias has been the

74 A well-known portrayal of stereotyped "Sindhi Hindi" in Indian popular media is that of the character Bijlani in the 1993 Bollywood film Hum Hain Rahi Pyar Ke. Played by Sindhi actor Dalip Tahilramani, Bijlani peppers his Hindi with utterances of /are/, the Sindhi imprecation /muā/ "O dead one!," and conflation of the sounds /r/ and / $\mathrm{r} /$, along with the occasional longer phrase completely in Sindhi ("Hum Hai Rahi Pyar Ke (HD) | Aamir Khan | Juhi Chawla | Kunal Khemu | Bollywood Comedy Movie," YouTube video, 2:33:59, posted by "Shemaroo Movies," May 2019 (https://youtu.be/1g8vuEt2lMQ?t=6629 [accessed March 16, 2021]).

75 Daswani and Parchani, ${ }^{6}{ }^{-57}$.

76 Daswani and Parchani, 27. 
frequent jettisoning of the common Sindhi surname suffix /-ānī/, meaning "descendant of," by several members of the first and second post-Partition generations in India. As the /-ânī/ surname suffix is a conspicuous marker of the bearer's Sindhi roots, it is unsurprising that discrimination would have caused several community members to do away with the suffix and blend into their environment. ${ }^{77}$ Chander Daswani interprets surname truncation as a sign of the bearer distancing themselves from their Sindhi identity, for which the bearer has tacit personal responsibility. ${ }^{78}$ In contrast, sociologist Rita Kothari's account of Sindhis in Gujarat hints at the phenomenon resulting from subliminal compulsion, traceable to the discrimination experienced by the community in that state compared to other states like Maharashtra. ${ }^{79}$

Whatever the reasons behind surname truncation, the practice has resulted in a phenomenon that seems to have evaded academic scrutiny thus far. We refer here to the frequent modification of /-ānī/ as [-ānī], where the retroflex or "hard" /ṇ/ (Perso-Arabic ैं; Devanagari ण) is replaced with an alveolar or "soft" [n] (Perso-Arabic ن; Devanagari न), both in speech and in writing. The reason for this modification is yet unclear. On the one hand, one can hypothesize that, since hard $/ \mathrm{n} /$ is absent in the sound system of English, English-dominant Indian Sindhis may unwittingly substitute soft $[\mathrm{n}]$ in its place. On the other hand, hard / $\mathrm{n} /$ is a distinct sound unit in Hindi, Marathi, and Gujarati, and many Indian Sindhis are proficient in one or more of these languages. Therefore, the reasons behind the shift in pronunciation of /-ānī/, particularly given its identitarian significance, merits closer examination. In the absence of detailed studies on the phenomenon, we surmise based on related research and our lived experience that certain members of the Indian Sindhi community may sociolinguistically view the pronunciation of the retroflex or hard /n/ as less sophisticated or prestigious. ${ }^{80}$ Given the importance of a personal

77 Ibid., $87-89$. However, Daswani and Parchani also state that "93\% of the [100] informants indicated that they were not ashamed of being recognized as Sindhis" (87).

78 Chander Daswani, "Language Attrition: The Case of Indian Sindhi," Oceanic Linguistics Special Publications 20 (1985): 191-198 (http://www.jstor.org/stable/20006722 [accessed March 16, 2021]).

79 Rita Kothari, The Burden of Refuge: The Sindhi Hindus of Gujarat (Delhi: Orient Longman, 2009).

8o Reporting on the English pronunciation of Indian-origin South Africans, linguist Rajend Mesthrie writes, "the more 'public' or 'formal' the speech, the less retroflexion; the more vernacular the context ... the greater the likelihood of retroflexion" (Rajend Mesthrie, "Indian South African English: Phonology," in Varieties of English: Africa, South, and Southeast Asia, ed. Rajend Mesthrie [Berlin: Mouton de Gruyter 2008], 195). This observation may suggest that the more retroflexed or "harder" the pronunciation of /t $\mathbf{d} \mathrm{n} /$ in 
name to the individual, the perceived negative connotations of hard [n] likely results in certain individuals preferring the softer [-ānī] pronunciation for their surnames.

The shift in pronunciation also has implications for writing. In the Devanagari orthography for both Sindhi and Hindi, /-ānī/ with hard [ṇ] is written ரणी, while [-ānī] with soft [n] is written If. Accordingly, Sindhi surnames may end up being spelled differently in Devanagari, seemingly on an ad-hoc basis. A striking example of the pervasiveness of such variation is in Figure 1, on Indian postage stamps featuring Sindhi revolutionary Hemu Kalani (19231943) and Sindhi politician Jivatram Kripalani (1888-1982). Even to a nonreader of Devanagari, it is evident that the Devanagari transcription of "Kalani" ends with णी and that of "Kripalani" with Iनी. Curiously, both stamps were designed and issued by the same government agency, India Post, making the spelling variation all the more intriguing.

Since the language-ecological motivation behind this phenomenon and its related grapholinguistic manifestation remains uncertain, we identify this as a good topic for further empirical testing and investigation.
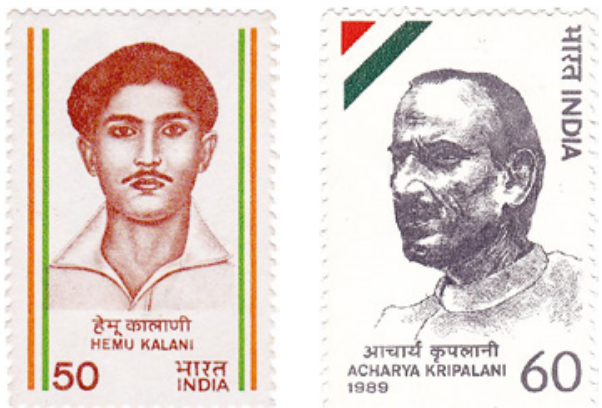

FIGURE 1 Variable manifestation of /-ānī/ in Devanagari Sindhi orthography INDIA POST, GOVERNMENT OF INDIA, 1983 (HTTPS://EN.WIKIPEDIA.ORG/ WIKI/HEMU_KALANI\#/MEDIA/FILE:HEMU_KALANI_1983_STAMP_OF_INDIA. JPG [ACCESSED MARCH 16, 2021]); INDIA POST, GOVERNMENT OF INDIA, 1989 (HTTPS://EN.WIKIPEDIA.ORG/WIKI/FILE:ACHARYA_KRIPALANI_1989_ STAMP_OF_INDIA.JPG\#/MEDIA/FILE:ACHARYA_KRIPALANI_1989_STAMP_ OF_INDIA.JPG [ACCESSED MARCH 16, 2021]). COPYRIGHT GOVERNMENT OF INDIA, LICENSED UNDER THE GOVERNMENT OPEN DATA LICENSE - INDIA (HTTPS://DATA.GOV.IN/SITES/DEFAULT/FILES/GAZETTE_NOTIFICATION_ OGDL.PDF [ACCESSED MARCH 16, 2021])

an individual's speech, the greater the likelihood that people will judge that individual's speech as unrefined or unpolished. 


\subsection{Presence: Multiscriptal History, Monoscriptal Ideology}

In the linguistics literature, Sindhi is often held up as the poster child of a South Asian language written in multiple scripts, and for good reason. Over the last millennium, written Sindhi - taken together with related varieties like Kachchhi - has been written in many writing systems. ${ }^{81}$ In 1853 , the British colonial government of Sindh instituted a nominally standardized version of the Perso-Arabic script as the official script for Sindhi. However, there remained several unresolved issues of spelling, especially regarding vowel signs. ${ }^{82}$ Notwithstanding the official status of Perso-Arabic, everyday use of other scripts for the language continued until Partition. In post-Partition Sindh, Perso-Arabic has prevailed as the undisputed script for the language, with Devanagari-script Sindhi restricted mainly to domains of academic interest, as in publications brought out by the Sindhi Language Authority in Hyderabad, Sindh..$^{83}$

On the other hand, post-Partition, India has witnessed a fierce and emotional debate regarding the script for Sindhi in the country. While discussion of the most appropriate writing system for the language had persisted ever since the British initially established a presence in Sindh, the debate got new life shortly after Partition. ${ }^{84}$ Questions about which script to use for Sindhi in India have given rise to a rich body of literature comprising popular advocacy and academic analyses. ${ }^{85}$ In "Acculturation," Khubchandani affirms the chasm between Perso-Arabic and Devanagari supporters, noting that the debate had "sharply divided ... Sindhi public opinion"86 Nevertheless, he also observes that most Sindhi publications and several schools in Maharashtra and Gujarat - where many Sindhis settled following Partition - continued to employ the Perso-Arabic script for the language. ${ }^{87}$ Just fifteen years later, Daswani and Parchani in Sociolinguistic Survey note that the divide had become tripartite, split almost equally among Perso-Arabic supporters, supporters

\footnotetext{
81 Arvind V. Iyengar, "A Diachronic Analysis of Sindhi Multiscriptality," Journal of Historical Linguistics (https://doi.org/10.1515/jhsl-2019-0027 [accessed March 16, 2021]).

82 Lekhwani, 38.

83 Fehmida Hussain, Sindhīa jī Sikhyā: Devanāgarī (Hyderabad, Pakistan: Sindhi Language Authority, 2011).

84 Matthew A. Cook and Maya Khemlani David, "Language Shift and Identity Reproduction among Diaspora Sindhis in India and Southeast Asia," Modern Asian Studies 55.3 (2020): 734-763.

85 Ibid., $7^{-15}$.

86 Khubchandani, "Acculturation," 33-34.

87 Ibid.
} 
of Devanagari, and those with no opinion on the script issue. ${ }^{88}$ Parchani in "Changes" affirms that the youngest generation of Sindhis mainly was indifferent to the script debate and that, to the extent they read and wrote in Sindhi, they did so in Devanagari more for reasons of competence rather than of conscious preference. ${ }^{89}$

Parchani's observations on competence being the decisive factor in script choice are frequently ignored as an aspect of this phenomenon. In "Sindhī Multiscriptality," Iyengar goes on to confirm how script competence ultimately decided how community members read and wrote in Sindhi, if they did so at all. ${ }^{90}$ His study also unearths how preference for a particular script, be it Perso-Arabic, Devanagari or Roman, does not necessarily mean that the person in question could or would actively read and write Sindhi in that script. In terms of competence, Iyengar points out that competence in Perso-Arabic among study participants under forty years of age was practically absent, but that this demographic was the most desirous of preserving the Perso-Arabic script for Sindhi. To a certain extent, the desire on the part of the under4Os may be illustrative of Hansen's Law, postulated by American historian Marcus Lee Hansen, in that "what the son wishes to forget, the grandson wishes to remember." ${ }^{\text {91 }}$ Quoting the sociolinguist Florian Coulmas, Iyengar observes that:

Perso-Arabic supporters were mostly nonliterate in [the script], and wanted to preserve the script for posterity rather than for practical reasons. Such participants were not concerned with what was in the text, but with what spoke to the eye. ${ }^{92}$

88 Daswani and Parchani, 93-95.

89 Parchani also alludes to a rising community feeling about the script being dispensable to language maintenance, in observing that younger Sindhis at the time felt "it was more important to maintain the language than harp on the issue of script, for, clearly, the [youngest] generation was not interested in this ongoing controversy" (Parchani, 9). This aspect is treated further in the next section of the article.

9o See also Iyengar, "Diachronic Analysis," for how competence-based script choice has historically been the norm in the Sindhi community rather than the exception.

91 Eugene I. Bender and George Kagiwada, "Hansen's Law of ‘Third-Generation Return' and the Study of American Religio-Ethnic Groups," Phylon 29.4 (1968): 360-370 (https://www .jstor.org/stable/27402 [accessed March 16, 2021]).

Coulmas, 32; Iyengar, "Sindhī Multiscriptality," 183. 
In contrast, study participants over sixty-five years of age were generally open-minded on which script to use for the language, as long as the language itself was kept alive:

Traditionalist Devanāgarī supporters were all literate in Perso-Arabic, and in principle, open to any solution that would encourage language maintenance. ${ }^{93}$

On the one hand, putting aside emotion and tradition, Devanagari was seen as the most practical option for Sindhi in India. On the other hand, community members also felt that restricting one's domain to India was myopic, given the sizable Sindhi diaspora that exists worldwide. Based on this thinking and the future in mind, some community members leaned towards the Roman script as the most pragmatic choice.

Indeed, since the early years of the twenty-first century, certain groups in India and overseas have advocated for Roman as a primary or auxiliary script for the Sindhi. The eponymous Romanized Sindhi group is foremost among such advocacy groups. This group draws on Sindhi community enthusiasts worldwide. The group has put forward a Roman-based spelling system for Sindhi, with the dual aim of skirting the script controversy and facilitating heritagelanguage literacy transfer for young Sindhis worldwide, many of whom have been educated in English. ${ }^{94}$ Whether Roman will emerge as one of the scripts, or the primary script, for Sindhi in India remains an open question. Regardless, it represents a fruitful avenue for sociolinguistic observation and research.

\subsection{Nonscriptal Future? The Neovernacularization of Indian Sindhi}

Irrespective of the persistent debates on the most appropriate script for Sindhi in India, the fact remains that the language has survived in the country mainly in the oral mode. Since Partition, and despite - or due to - the script debates, the societal prominence of Sindhi in the written form has decreased considerably, be it in mass media or the number of schools offering education in Sindhi. In the latter context, Iyengar notes that schools teaching in Sindhi as the medium of instruction are almost nil. To the extent available, Sindhi is offered as a language subject in select schools in certain states. ${ }^{95}$

93 Ibid.

94 See the movement's website at http://www.romanizedsindhi.org/ (accessed March 16, 2021).

95 Iyengar, "Sindhī Multiscriptality," 52 . 
Such recession from the public domain, especially in written literature and formal education, is another example of Sindhi's behavioral adaptation based on ecological pressures, embodying Mohanty's analogy of a minority language surviving by receding from predators. That said, and unlike the minority tribal languages that Mohanty references, Sindhi in India represents a written language with a rich literary tradition that has become spoken-only all over again. In "Multilingualism and language decay," Daswani notes that "Indian Sindhi presents an instance of a fully elaborated and accepted language falling into disuse." ${ }^{.96}$ Linguist Elayaperumal Annamalai identifies a similar process occurring with Tamil and dubs the process neovernacularization. According to Annamalai, a language with a standardized written form and literary history is neovernacularized when:

[T] he economic, political and cultural value of [that] language comes to near zero ... such a language survives, but does not live. This situation can be found even in a language with a large population and official status. ${ }^{97}$

The neovernacularization of Sindhi probably carries the most crucial lessons for our understanding of the language's existence in independent India. For starters, it is precisely the ongoing neovernacularization of Indian Sindhi that has, to a great extent, triggered linguistic and cultural anxiety among older community members, due to the "out of sight, out of mind" situation the phenomenon creates. ${ }^{98}$ The disappearance of Sindhi from the prestigious and visually salient written domain appears to have created a subjective impression that the language is altogether vanishing from society. However, as described at the start of this article, the fear of Sindhi fading into oblivion has not materialized. Instead, government census figures have indicated the opposite for over seven decades now.

More importantly, while Annamalai's conceptualization of a language undergoing neovernacularization may come across as a negative, or at least pessimistic outcome, the phenomenon is also not unusual in the Indian context. As mentioned, Annamalai first proposed the term for a similar process occurring with Tamil in India - a language that, unlike Sindhi, is the official

\footnotetext{
96 Daswani, "Multilingualism and Language Decay," 6o.

97 Elayaperumal Annamalai, "Death by Other Means: Neovernacularization of South Asian Languages," in Language Endangerment and Preservation in South Asia, ed. Hugo C. Cardoso (Honolulu, HI: University of Hawai'i Press, 2014), 3.

98 Kothari, 163 . Such anxiety has also resulted in the oxymoronic characterization of Sindhi being an ancient and rich language on the one hand but doomed to extinction on the other.
} 
and majority language of an Indian state. ${ }^{99}$ Indeed, within the broader South Asian linguistic ecology, history shows that languages' literary glory and status has waxed and waned, defying simplistic characterization. Prominent in this context is Urdu, a register that emerged in Delhi and, in pre-Partition times, was the vehicle of much-written poetry and prose across northern South Asia. In contrast, Urdu's societal status and literary presence are diminishing in present-day India, including in its birthplace of Delhi. ${ }^{100}$ Also relevant is the situation of Punjabi in South Asia. While Punjabi today has more than twice as many speakers in Pakistan as in India, it is in India that the language continues to have a literary presence and is used in education, government, media, and literature. In Pakistan, Punjabi remains widely known and used, but mainly in the oral mode. ${ }^{101}$ In a sense, the present-day situation of Punjabi is almost precisely the inverse of Sindhi's, with the former being neovernacularized in Pakistan and the latter in India. Finally, Tulu in southern India, native to a thriving mercantile community not unlike the Sindhis, had a nominal written presence in the past but is almost entirely unwritten today. Yet, it continues to be maintained orally in the domestic and community domains. ${ }^{102}$

Thus, while Urdu, Punjabi, and Tulu may be considered neovernacularized languages, at least in certain parts of South Asia, they also continue to be maintained as a home language in spoken form. Indeed, maintaining a distinct oral-only home language for generations is not unusual in the Indian language ecosystem. As linguist A.K. Srivastava writes:

[The] presence of several languages in the immediate as well as remote environment ... has been the greatest language teacher in India and has also helped in maintaining multilingualism informally at the oral level through the ages. ${ }^{103}$

99 Annamalai, 3.

100 Christopher R. King, One Language, Two Scripts:The HindiMovement in Nineteenth-Century North India (Delhi: Oxford University Press, 1994). On a side note, while linguists may argue that Urdu and Hindi are different registers or styles based on a near-identical grammar, laypersons typically think of them as distinct "languages," based mainly on their starkly different scripts.

101 Shackle, 638-640.

102 Malavika Shetty, "Language Contact and the Maintenance of the Tulu Language in South India," Texas Linguistic Forum 47 (2003): 183-195 (http://salsa.ling.utexas.edu/proceedings/2003/shetty.pdf [accessed March 16, 2021]).

103 A.K. Srivastava, "Multilingualism and School Education in India: Special Features, Problems, and Prospects," in Multilingualism in India, ed. Debi Prasanna Pattanayak (New Delhi: Orient Longman, 199o): 42. 
Against this background, neovernacularization and oral-only home maintenance of Indian Sindhi are not unique or unusual in the Indian linguistic ecosystem. In this regard, Iyengar notes that:

[U]se of the traditional community language in restricted domains, and implicit tolerance of neo-vernacularization and language shift are not unusual in the urban milieus in which the Indian Sindhī community typically finds itself, both in India and overseas. ${ }^{104}$

While neovernacularization of a language comes with pedagogical and cultural implications, the phenomenon has also been a regular and frequent occurrence in the linguistic ecosystem of the Subcontinent. In this regard, the apparent neovernacularization of Sindhi in independent India is, in a sense, unsurprising. After seven-and-a-half decades of being implanted in India, Sindhi has lost a large part of its literary status and a population literate in it. However, over the same period, the language has been maintained orally in the home. It has also been registering uninterrupted decadal growth. Therefore, while it is undeniable that a robust written tradition contributes to language maintenance, such a tradition does not appear to be indispensable for language maintenance, as evinced by the case of Sindhi in post-Partition India. Indeed, the maintenance of Sindhi as a spoken-only neovernacularized language throws up crucial questions on the role of a written form in language maintenance, challenging existing theories on the topic. ${ }^{105}$

For a lay Sindhi community member, the neovernacularization of the language in India may be a bittersweet occurrence. The fading away of written Sindhi from the Indian linguistic landscape coincides with the gradual passing of script activists on all sides of the debate, with those still amongst us being of advanced age. That said, the waning of this cohort is also hastening the demise of the Sindhi script debate in India. Given that people have maintained spoken Sindhi in India without a resolution of the script debate, the question of which writing system to use for Sindhi in India for language maintenance is increasingly receding into the background. The progressive retreat of the script issue is illustrated in the recent emergence of Sindhi-language channels and content on social media by Indian creators, which feature the oral language with little or no depiction of the written language. ${ }^{106}$

104 Iyengar, "Sindhī Multiscriptality," 24. Also, see Cook and David.

105 Fishman, 39-41.

106 For example, see the YouTube channel "Sindhi Film Festival" curated by Bhavna Rajpal. It features Sindhi-language interviews of litterateurs, educationists, and personalities. 
Of course, the script's dispensability in connection to language maintenance is not a pretext to cease pedagogical, lexicographic, scholarly, or popular work in the Perso-Arabic and Devanagari writing systems. As Iyengar notes in "Variation," contemporary society accords greater prestige to written languages than spoken-only ones. ${ }^{107}$ Sindhi in India may continue to be maintained on an oral level and symbolically valued. However, it still lacks the status and prestige of socioeconomically beneficial languages such as English and Hindi. ${ }^{108}$ For this reason, while the Sindhi language has unquestionably survived in post-Partition India, it has not thrived.

The evidence presented in this article attests to the Sindhi language having defied the odds and endured in independent India for three-quarters of a century. This fact is attributable to the language's adaptation to its post-Partition environment. This adaptation can be seen in ongoing changes over the years in the language's form, function, and presence to harmonize with its surrounding languages. Indeed, it is likely the quiet adaptation of the language with its environment that has caused its survival to escape widespread attention. The continuity and growth of the language in independent India for nearly seventy-five years now carries valuable lessons for our understanding of language ecology and the connection between language and identity, both in the broader Indian context and within the Indian and diasporic sections of the Sindhi community.

Over the past seven decades, while spoken and maintained at a community level, Sindhi has steadily lost out to English as the preferred language of education, as a medium of instruction, or even as a language of written communication. As is often the case with orally-maintained languages in India, while Sindhi speakers may have a certain level of emotional or cultural attachment to the language, they also seem to be implicitly aware of its limitations as a vehicle of socio-economic progress. In sum, the reasons for Sindhi's survival in post-Partition India appear consistent with those of other minority languages in the country, namely, oral maintenance in the home domain for

While the spoken language is front and center in these videos, the written language in Perso-Arabic, Devanagari or Roman plays only a secondary role (https://www.youtube .com/channel/UCMyF3wzNMnZN2sQjbYPIv4w [accessed March 16, 2021]).

107 Iyengar, "Variation," 193.

108 Iyengar, "Sindhī Multiscriptality," 23-26. 
generations, while simultaneously receding into the background and away from the public sphere, becoming inconspicuous in the linguistic ecosystem. This situation meets Ajit Mohanty's characterization of a minority language surviving by exhibiting "anti-predatory" sociolinguistic behavior. Applying Mohanty's definition, Sindhi in India has "retreat[ed] to areas of lesser access and visibility and low resources" and "restricted to domains of home and in-group communication and other less significant domains." 109 In other words, the survival and nominal growth of Sindhi in India have come at the cost of social visibility, including within the Sindhi community itself.

However, things may stand at a turning point. In recent years, technological advancements have proven to be a veritable shot in the arm for minority language varieties worldwide. Spoken-language content can now be directly propagated on mobile devices and social media without recourse to a written form. Whether this heralds the start of a technology-driven language renaissance for Sindhi in India remains to be seen. In this regard, the impact of technology on facilitating contact between Sindhi speakers worldwide, bridging script and geopolitical divides, represents fertile grounds for future linguistic and sociological research. In addition, a fortunate outcome of the creeping invisibilization of Sindhi in India has been a renewed interest in Sindhi culture and history, particularly the Partition experience and pre-Partition life in Sindh. ${ }^{110}$ Such works represent a much-needed popular complement to scholarly output on Sindh and Sindhis in the sociological, anthropological, and linguistic domains. This surge in curiosity and inquiry is not dissimilar to biological species often receiving more attention when perceived as vulnerable.

In the context of scholarship, the phenomenon of the Sindhi community remaining coherent and cohesive worldwide, despite language shift in many quarters, has been the subject of much academic inquiry. Furthermore, the phenomenon of "cohesiveness despite language shift" among diasporic Sindhis has thrown up a challenge to the dominant academic discourse of a community's heritage language being a necessary and sufficient marker of its identity.111 Indeed, aside from intellectuals and cultural activists, the Sindhi community

109 Mohanty, 266.

110 See, for example, Nandita Bhavnani, The Making of Exile: Sindhi Hindus and the Partition of India (Chennai, India: Tranquebar Press, 2013); Saaz Aggarwal, Sindh: Stories from a Vanished Homeland (Pune, India: Black-and-White Fountain, 2012).

111 David provides a pithy summary of this phenomenon when she writes that, for Malaysian Sindhis, "the Sindhi language is no longer a sine qua non for Sindhiness" (Maya Khemlani David, "Language Shift, Cultural Maintenance, and Ethnic Identity; A Study of a Minority Community: The Sindhis of Malaysia," International Journal of the Sociology of Language 130 [1998]: 75 (http://dx.doi.org/10.1515/ijsl.1998.13o.67 [accessed March 16, 2021]). 
outside of Sindh, whether in India or elsewhere, generally seems to have an easy-going relationship with its traditional language. Such a relaxed attitude is sometimes criticized as indifference towards their culture and identity. However, as Mark-Anthony Falzon succinctly observes in his anthropological study on the Sindhi diaspora worldwide:

Sindhis generally tend to keep a low profile wherever they are settled; moreover, they generally adapt swiftly to local lifestyles in terms of dress, food, language, etc. Thus, they often fail to live up to the model of a distinctive bounded culture that anthropologists traditionally were so keen on. ${ }^{112}$

To this end, the parallels between community and language, albeit anecdotal, are nevertheless palpable. In many ways, the Sindhi language in India has lived up to the stereotypes commonly associated with the Sindhi diaspora: largely inconspicuous, yet adaptable and enduring, even in the face of adversity, to the extent that such adaptability gets criticized as identitarian apathy. Nevertheless, this very adaptability has enabled the survival of both community and language in many environments. As the oft-cited sociolinguistic cliché goes, the only language that does not change is a dead language. Three-quarters of a century after Partition, Sindhi in India is anything but a dead language.

\section{Notes on Contributors}

Arvind lyengar, Ph.D., is Lecturer in Linguistics at the University of New England, Australia, and a member of the UnE Asia Pacific Network.

Sundri Parchani, Ph.D., is a linguist and poet based in Pune, India, with interests and extensive experience in the grammar and sociolinguistics of Sindhi in India.

112 Mark-Anthony Falzon, Cosmopolitan Connections: The Sindhi Diaspora, 186o-2000 (Leiden and Boston: Brill, 2004), 2. Also, see Cook and David. 